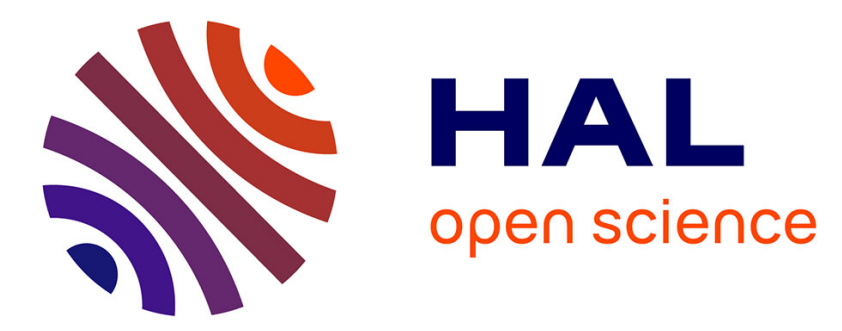

\title{
Alcohol delamination in the treatment of recurrent corneal erosion: an electron microscopic study
}

Rita Mencucci, Iacopo Paladini, Brunilda Brahimi, Ugo Menchini, Harminder Singh Dua

\section{- To cite this version:}

Rita Mencucci, Iacopo Paladini, Brunilda Brahimi, Ugo Menchini, Harminder Singh Dua. Alcohol delamination in the treatment of recurrent corneal erosion: an electron microscopic study. British Journal of Ophthalmology, 2010, 94 (7), pp.933. 10.1136/bjo.2009.174409 . hal-00557352

\section{HAL Id: hal-00557352 https://hal.science/hal-00557352}

Submitted on 19 Jan 2011

HAL is a multi-disciplinary open access archive for the deposit and dissemination of scientific research documents, whether they are published or not. The documents may come from teaching and research institutions in France or abroad, or from public or private research centers.
L'archive ouverte pluridisciplinaire HAL, est destinée au dépôt et à la diffusion de documents scientifiques de niveau recherche, publiés ou non, émanant des établissements d'enseignement et de recherche français ou étrangers, des laboratoires publics ou privés. 
Title: Alcohol delamination in the treatment of recurrent corneal erosion: an electron microscopic study

Authors: ${ }^{1}$ Rita Mencucci MD, ${ }^{1}$ Iacopo Paladini MD, ${ }^{1}$ Brunilda Brahimi MD, ${ }^{1}$ Ugo Menchini MD, ${ }^{2}$ Harminder S. Dua MD, PhD., ${ }^{3}$ Paolo Romagnoli MD

Affiliation: ${ }^{1}$ Department of Ophthalmology, University of Florence, Italy; ${ }^{2}$ Department of Ophthalmology, Queen's Medical Centre, University Hospital, Nottingham, United Kingdom;

${ }^{3}$ Department of Anatomy, Histology and Forensic Medicine, University of Florence, Italy

Keywords: Recurrent corneal erosion, alcohol delamination, electron microscopy, corneal epithelium.

Word count: 2615

Corresponding author:

Rita Mencucci:

Department of Oto-Neuro-Ophthalmological Surgical Sciences - Eye Clinic, Viale GB Morgagni 85, 50134 Florence, Italy

Tel.+39-055-411765

FAX.+39-055-4377749

E-mail: rita.mencucci@unifi.it

The Corresponding Author has the right to grant on behalf of all authors and does grant on behalf of all authors, an exclusive licence (or non exclusive for government employees) on a worldwide basis to the BMJ Publishing Group Ltd and its Licensees to permit this article (if accepted) to be published in BJO editions and any other BMJPGL products to exploit all subsidiary rights, as set out in our licence(http://group.bmj.com/products/journals/instructions-for-authors/licence-forms/). 


\section{Abstract (268 words)}

Purpose: To investigate by electron microscopy, the plane of separation of the epithelial sheet from its substratum in the procedure of alcohol delamination (ALD) in patients with recurrent corneal erosion syndrome.

Methods: Ten cases of recurrent corneal erosions (RCE) secondary to trauma and seven cases related to map-dot-fingerprint dystrophy (MDFP) were treated with ALD. The epithelial sheets obtained from these patients were examined by transmission electron microscopy. Similarly sheets obtained form twenty patients undergoing photorefractive keratectomy [ten by mechanical removal and ten by ALD] were also examined as control group. Five further corneal buttons obtained at keratoplasty were treated with ALD and the epithelial sheet and corresponding stroma were both examined.

Results: In all specimen whether removed mechanically or by ALD, the intercellular surfaces did not show any disruption and desmosomes were preserved. In patients with traumatic RCE and in corneal buttons obtained at keratoplasty, tissue separation occurred along the lamina lucida whereas in patients with MDFP the whole basal lamina was removed along with the epithelium. Focal areas of basal cell degeneration and epithelial detachment from the basal lamina were also noted.

Conclusions: ALD enables efficient removal of the epithelium with an almost complete preservation of the lamina densa in traumatic RCE. In RCE due to MDFP the epithelium separates from the stroma below the basal lamina and may reflect the pathology of the condition. 


\section{INTRODUCTION}

Recurrent corneal erosion (RCE) is characterized by episodes of spontaneous breakdown of the corneal epithelium due to defective adhesion to the basement membrane .[1]

It is believed that failure of the epithelial cells to regain and maintain tight adhesive contacts with the underlying stroma following injury plays a pivotal role in the pathogenesis of traumatic RCE. There are several theories about pathogenesis, including hemidesmosome weakness, alterations of the corneal basement membrane, in particular duplication and thickening, and activation of matrix metalloproteinases as part of an inflammatory process.[2,3]

The vast majority of patients develop RCE following mechanical trauma involving the basement membrane, while in some patients it may be secondary to a primary dystrophy of the epithelial basement membrane also known as map- dot-fingerprint dystrophy (MDFP). [4] MDFP is regarded by some authors to be related to an autosomal dominant genetic defect and by others as a non-hereditary corneal degeneration.[4,5] The disease is bilateral and frequently asymmetric, most frequently asymptomatic but sometimes causing pain. On clinical examination it is characterized by one or more features of map-like subepithelial patches (maps), epithelial microcysts (dots) and subepithelial ridges (fingerprints).[6] Typical findings at histology are an abnormal basement membrane protruding into the epithelium and intraepithelial microcysts.[7] Slit-lamp examination of RCE reveals punctate epithelial erosions in milder cases (microform erosions) and a frank epithelial defect or a large area of oedematous non adherent epithelium in severe cases (macroform erosion).[8]

Mild episodes of RCE can often be successfully managed by topical lubrication alone, but there are cases in which conservative measures fail. A number of treatments have been advocated for this group of patients, all of which report a high degree of success. These include soft, high water 
containing bandage contact lenses (BCL),[9] anterior stromal puncture,[10] neodymiumdoped:yttrium aluminium garnet (ND:YAG) laser puncture,[11] superficial keratectomy with a diamond burr [12] and phototherapeutic keratectomy (PTK).[13,14] These treatments have all been used successfully, but are limited by the risk of scarring at the visual axis, refractive changes or by cost and availability. [14]

Delamination of the corneal epithelium with dilute alcohol has become a valuable alternative for the treatment of recurrent corneal erosions. It seems to be a quick, safe and economical procedure which can achieve excellent clinical results. [15] Treatment needs to be undertaken in a controlled manner because the corneal epithelium is quite sensitive to alcohol damage, which is rapidly evident when contact between $20 \%$ ethanol and the epithelium is maintained for over 30 seconds, as demonstrated in laboratory mammals and humans. [16,17] The effects of alcohol on the epithelium being treated, in relation to the underlying pathology, are poorly defined despite its common usage in the LASEK procedure and in treating RCE.

Espana et al. studied normal corneas (without RCE) and provided immunohistochemical evidence that upon alcohol delamination (ALD) the basal lamina, as indicated by laminin 5 staining, is almost entirely left on corneal side while the basal cell membrane of the epithelium, as indicated by integrin $\beta 4$ staining, is removed almost entirely with the epithelial flap. Collagen VII, the constituent of anchoring fibrils, remains on the corneal side. [18]

Electron microscopic examination of epithelium removed with ALD from corneas, both affected or unaffected by RCE, has shown separation of the epithelium from the stroma at the level of the lamina lucida, with apparently intact hemidesmosomes on the basal epithelial surface.[8,19,20] Proteinaceous or cellular debris underneath the epithelium has also been demonstrated in patients with RCE. The path followed by alcohol to reach the basal layer and the relationship between the underlying disease and the response to alcohol application are still undetermined. To study these 
issues, we examined by electron microscopy the epithelium following by ALD to treat RCE either traumatic or related to MDFP, removal by mechanical debridement and by ALD in cases undergoing PRK and by ALD in corneal buttons removed at keratoplasty. The examination focused on the epithelial cells and the plane of cleavage.

\section{PATIENTS AND METHODS}

Seventeen subjects with RCE who had not responded to conservative measures were treated by ALD ( 7 males and 10 females, mean age 34 years \pm 7.9 ). Ten of them had traumatic RCE ( 5 male and 5 female, mean age 30 years \pm 5 ) and seven had RCE related to MPDF ( 2 males, 5 females, mean age 38 years \pm 4.4 ). The control group consisted of twenty patients undergoing photorefractive keratectomy (PRK) for refractive correction (10 males and 10 females, mean age 27.9 years \pm 4.2 ). In ten of them the epithelium was removed mechanically and in ten by ALD. Furthermore five corneal buttons removed from patients undergoing keratoplasty for traumatic leukoma (4 males and 1 female, mean age 36.5 years) were treated by ALD taking care to ensure that the delaminated epithelium was outside the area of leucoma. A $4 \mathrm{~mm}$ disc of epithelium was removed. The technique was as previously described .[8] All the patients gave informed, written consent to participate in the study. Tissue procurement and use was carried out in accordance with the declaration of Helsinki and local ethics regulations.

All procedures were carried out in an operating room under topical anaesthesia with oxibuprocaine cloridrate $0.4 \%$ (Novesina $0.4 \%$,Novartis Farma, Origgio, Italy) and instillation of $5 \%$ betadine into the conjunctival sac. Mechanical debridement was performed using a blunt spatula. For ALD, absolute ethyl alcohol was diluted to $20 \%$ with sterile water in a $1 \mathrm{~mL}$ syringe. A circular well sufficient to encompass the area of erosions (optical zone marker, 4-6 mm in diameter, Bausch and Lomb, Kingston-upon-Thames, Surrey, UK) was placed onto the cornea and held with firm downward pressure. A few drops of $20 \%$ alcohol were placed inside the well to cover the entire treatment area and left in place for 30 seconds. The alcohol was then drained with a surgical sponge 
(K-Sponge-Katena Products, Denville, NJ) and the well removed from the cornea. The surface of the eye was irrigated with balanced salt solution to wash away residual alcohol. Using a fresh, dry surgical sponge, the corneal epithelium was removed from the treated area as a single sheet. The corneal surface was gently irrigated again with balanced salt solution and BCL was inserted. The patients were treated with netilmicin drops $0.3 \%$ (Nettacin $0.3 \%$, preservative free, SIFI, Catania, Italy), four times a day, and topical lubricants (Optive UD, preservative free, Allergan Italia, Rome , Italy) four times a day. Topical medication was discontinued and the BCL removed after a couple of weeks. Corneal buttons were also similarly treated with alcohol.

All removed epithelial sheets and the denuded corneal buttons were immediately fixed with Karnovsky's mixture in $0.1 \mathrm{~mol} / \mathrm{L}$ cacodylate buffer, $\mathrm{pH} 7.4$, osmicated and embedded in epoxy resin. One-two micron thick sections were stained with alkaline toluidine blue and observed at light microscopy to select areas for electron microscopic analysis. Thin sections (about $70 \mathrm{~nm}$ ) were stained with uranyl acetate and lead citrate and observed in a 1010 electron microscope (Jeol, Tokyo, Japan), at $80 \mathrm{kV}$.

\section{RESULTS}

General features of the corneal epithelium

In all cases the corneal epithelium appeared as a multilayered sheet (Fig. 1A), with flat superficial cells joined by tight junctions and many desmosomes between cells in all layers (Fig. 1B). The cells were rich in tonofilaments, which formed a mesh filling most of the cytoplasm without aggregating into fibrils except in the immediate proximity to desmosomes.

Mechanical debridement versus alcohol delamination of control specimens. Upon mechanical debridement the basal epithelial layer was variably preserved. In most areas it appeared intact with a continuous plasma membrane and hemidesmosomes on the basal cell surface (Fig. 1C). In very few focal areas there were small patches of basal lamina adhering to the basal cell 
surface. However, proteinaceous material and cell blebs were often seen beneath the epithelium

(Fig. 1A, C). The basal cell desmosomes were as well preserved (Fig. 1B) as in the superficial cell layer (Fig. 1A).

The corneal epithelium in cases which underwent ALD during photorefractive keratectomy and in corneal buttons appeared similar to that seen upon mechanical debridement, with preservation of desmosomes (Fig. 2A). Here too the plasma membrane of the basal cells was intact with a few small patches of adherent basal lamina (Fig. 2B). Peculiar features were inhomogeneous cell density and nuclear alterations in some areas. In particular, dark cells were seen in the most superficial layers, intermediate electron dense cells deeper in the epithelium and pale cells even deeper; all these cells were rich in tonofilaments and demonstrated well preserved desmosomes (Fig. 2A). In the same or other areas, detachment of chromatin from the nuclear envelope was shown by the appearance of a halo of relatively clear granular material between the nuclear envelope and the most peripheral chromatin clumps (Fig. 2C). The stromal bed of the corneal buttons from whence the epithelium was removed by ALD showed the Bowman layer delineated by the lamina densa over most of its surface (Fig. 2D). Occasional anchoring fibrils were attached to the deep aspect of the lamina densa.

Alcohol delamination for traumatic RCE Epithelial specimens obtained by ALD from cases of traumatic RCE appeared similar to those from ALD treated controls (Fig. 3A), with all cells rich in tonofilaments and well preserved desmosomes (Fig. 3B). The basal lamina did not come off with the epithelium (Fig. 3C) except where small patches of basal lamina remained attached to the epithelium; it was made up of a single or a few anastomosed layers of basal lamina. A few anchoring fibrils could be seen extending from the deep aspect of the basal lamina (Fig. 3D). Well preserved hemidesmosomes were visible on the basal surface of the basal cell layer (Fig. 3C, D). Electron dense material and vesicular debris were present underneath the basal cell layer in a few areas. Here too, alcohol induced artefacts were sometimes seen, i.e. inhomogeneous cytoplasm density among cells and chromatin detachment 
from the nuclear envelope. Morevover, peculiar alterations in these samples were epithelial atrophy and interruptions of the basal cell layer in some areas (Fig. 4A), while in other areas there was lack of hemidesmosomes and an irregular profile of the deep surface of the basal cells including thin projections consistent with the appearance of filopodia or lamellipodia, with intact basal cell membrane and no signs of degeneration in the cytoplasm (Fig. 4B).

\section{Alcohol delamination for RCE in MDFP}

Upon ALD for RCE in MDFP_a thick ( $5 \mu \mathrm{m}$ or more) layer was seen attached beneath the basal cell layer (Fig. 5A). This layer was composed of several, incomplete, anastomosing layers of basal lamina attached to many anchoring fibrils. The basal lamina close to the epithelium showed several, small interruptions and the basal cells showed several hemidesmosomes some of which were separated from the basal lamina (Fig. 5B, C). There were foci of intercellular edema, with disruption of desmosomes and vesicular debris (Fig. 5A).

\section{DISCUSSION}

Conventionally, the term 'basal lamina' is used to describe the electron microscopic features of the extracellular matrix on which the epithelial layers sit. It is made of and electron lucid superficial layer, the lamina lucida, composed largely of the glycoprotein laminin and an electron dense deeper layer, the lamina densa, composed largely of type IV collagen. Both these layers are secreted by the epithelial cells. Deeper to the lamina densa is a 'lamina reticularis' which contains fibronectin and other connective tissue elements. In squamous epithelia, the reticular lamina is secreted by the underlying stromal cells. These separate layers are indistinguishable on light microscopy and the laminae lucida, densa and reticularis are together referred to as the basement membrane.

This study has demonstrated that there are some differences in the morphology of the epithelial sheets removed by ALD in patients with trauma related RCE and those with MDFP dystrophy. In traumatic RCE the cleavage plane was primarily between the basal cells and the basal lamina. These 
findings were similar to those seen in the control samples obtained from patients who did not have RCE but were being treated in a similar manner with PRK (Lasek). Hemidesmosomes remained attached to the epithelial sheet removed. This also concurred with findings seen in corneal buttons removed at keratoplasty and treated with ALD. In cases with MDFP dystrophy with RCE, the thick, multilayered basal lamina was removed entirely with the epithelium.

Alterations in intracellular content affecting both nuclei and cytoplasm together with preservation of intercellular desmosomal attachments would indicate that alcohol passes through, rather than in between cells to reach the subepithelial stroma. Cells of different electron density were seen in ALD specimen with the most dense ones being more superficially located and with uniform density across each single cell. This finding was alike in control specimens and in those from RCE, so it cannot be attributed to the disease but should be related to treatment; it would suggest that alcohol is capable of passing through cells and that the cell membrane allows permeation of alcohol whilst retaining its morphological integrity. The patchy nature of the changes observed would imply that the penetration of alcohol was not uniform across the area of contact resulting in variable exposure of cells under the area of contact.

Examination of the corneal buttons and of the epithelial sheets removed both from controls and from cases of RCE showed that the lamina densa was not removed with the epithelium but remained attached to the underlying stroma. This indicates that epithelial delamination took place in general at the level of the lamina lucida of the basal lamina. Although this was the dominant picture there were areas where some cells appeared damaged with accumulation of extracellular proteinaceous material and cell debris underneath. In other areas delamination occurred beneath the basal lamina, which remained attached to the epithelium. These inequalities in the level of delamination could be related to the effect of alcohol or the mechanical intervention required to physically remove the alcohol treated sheet. There was no correlation observed between the level of 
delamination and the intracellular alterations noted such as non-uniform electron density of cells and separation of chromatin from the nuclear envelope. This would indicate that the effects of alcohol on the cells and on the basal lamina are independent of each other. These features were seen both in control specimens and in those from RCE, so they could not be attributed to the disease but rather should be ascribed to the delamination procedure. It was also of interest to note that mechanical debridement was also associated with changes very similar to those seen with ALD, but the epithelium was more frequently damaged. This would point to a natural cleavage plane at the level of the lamina lucida. A previous study had shown that mechanical debridement is also associated with damage to the underlying stroma,[19] therefore we suggest that ALD should be preferred to mechanical debridement for the treatment of RCE, judging from a histological point of view.

Our electron microscopic findings, as far as controls are concerned, match well with the immunohistochemical findings reported by Espana et al.[18] These authors did not analyse cases of RCE. On the other hand our findings do not correlate with those reported by Chen et al. who examined, by immunohistochemistry, epithelial sheets removed mechanically from corneas with RCE.[21] The found laminin 5 (lamina lucida and densa) and collagen VII (lamina reticularis) in the epithelial sheet suggesting that their mechanical effort was more forceful and took them to a deeper plane. Retention of the lamina densa on the denuded stroma, as is normally the case with ALD, would leave behind a smooth surface facilitating the migration and adhesion of regenerating epithelial cells.

The occasional finding in RCE, but not in control specimens, of cells with intact basal cell membrane but devoid of hemidesmosomes and with an irregular profile including thin projections of filopodia or lamellipodia (the distinction between the two being impossible at electron microscopy) may be interpreted as an expression of a repair processes consequent to an erosion, 
with cells still able to move and not yet firmly attached to the basal lamina. In particular, the lack of hemidesmosomes in the presence of an intact basal cell membrane and in the absence of alterations in the cytoplasm is compatible with cell migration and reshaping but not with cell pathology. The limited areas of epithelial atrophy should be indicative of incomplete repair of previous erosions.

The difference observed with MDFP dystrophy where the thickened basal lamina was removed completely with the epithelium is novel. Despite signs of degeneration of the basal cell layer with intercellular oedema, occasional cell death and hemidesmosome detachment, the basal lamina was more adherent to the epithelial sheet than to the underlying stroma. These findings also suggest that in this type of dystrophy a derangement in the molecular and ultrastructural organization of the anterior corneal stroma may contribute to the occurrence of erosions.

\section{COMPETING INTERESTS}

None of the authors of this paper had any competing interests. 


\section{REFERENCES}

1 Kanski JJ. Clinical Ophthalmology. 4th ed. Boston: Butterworth- Heinemann; 1999:139-40

2 Goldman JM, Dohlman CH, Kravitt BA. The basement membrane of the human cornea in recurrent epithelial erosion syndrome. Trans Am Acad Ophthalmol 1998;82:26-8.

3 Garrana RM, Zieske MA, Assouline M, et al. Matrix metalloproteinases in epithelia from human recurrent corneal erosion. Invest Ophthalmol Vis Sci 1999;40:2506-12.

4 Reidy JJ, Paulus MP, Gona S. Recurrent erosions of the cornea: epidemiology and treatment. Cornea 2000; 19:767-71.

5 Laibson PR. Microcystic corneal dystrophy. Trans Am Ophthalmol Soc 1975;74:483-531.

6 Dighiero P, Ellies P, Grateau G, et al. Review on corneal dystrophies. J Fr Ophtalmol 1999;22:226 -33.

7 Cogan DG, Kuwabara T, Donaldson DD et al.. Microcystic dystrophy of the cornea: a partial explanation for its pathogenesis. Arch Ophthalmol 1974;92:470-4.

8 Dua HS, Lagnado R, Raj D et al. ALD of the corneal epithelium: an alternative in the management of recurrent corneal erosions. Ophthalmology 2006;113:404-11. 
9 Kenyon KR. Recurrent corneal erosion: pathogenesis and therapy. Int Ophthalmol Clin 1979;19:169-95.

10 Rubinfield RS, Laibson PR, Cohen EJ, et al. Anterior stromal puncture for recurrent erosions: further experience and new instrumentation. Ophthalmic Surg 1990;21:318-26.

11 Geggel HS. Successful treatment of recurrent corneal erosions with ND:YAG anterior stromal puncture. Am J Ophthalmol 1990;110:404-7.

12 Sridhar MS, Rapuano CJ, Cosar BC, et al. Phototherapeutic keratectomy versus diamond burr polishing in the treatment of recurrent corneal erosions associated with anterior basement dystrophy. Ophthalmology 2002;109:674-9.

13 Maini R, Loughnan MS. Phototherapeutic keratectomy re-treatment for recurrent corneal erosion syndrome. Br J Ophthalmol 2002;86:270-2.

14 Hykin PG, Foss AE, Dart J, et al. The natural history and management of recurrent corneal erosion: a prospective randomised trial. Eye 1994;8:35-40.

15 Singh RP, Raj D, Pherwani A et al. Alcohol delamination of the corneal epithelium for recalcitrant recurrent corneal erosion syndrome: a prospective study of efficacy and safety. $\mathrm{Br} J$ Ophthalmol 2007;91:908-11

16 Kim SY, Sah WJ, Lim YW et al. Twenty percent alcohol toxicity on rabbit corneal epithelial cells. Electron microscopic study. Cornea 2002; 21: 388-392. 
17 Chen CC, Chang JH, Lee JB et al. Human corneal epithelial cell viability and morphology after dilute alcohol exposure. Invest Ophtahlmol Vius Sci. 2002; 43: 2593-2602.

18 Espana EM, Grueterich M, Mateo A et al. Cleavage of corneal basement membrane components by ethanol exposure in laser-assisted subepithelial keratectomy. J Cataract Refract Surg. 2003;29:1192-7.

19 Browning AC, Shah S, Dua HS et al. Alcohol debridement of the corneal epithelium in PRK and LASEK: an electron microscopic study. Invest Ophthalmol Vis Sci. 2003; 44-510-513.

20 Pallikaris IG, Naoumidi II, Kalyvianaki MI et al. Epi-LASIK: comparative histological evaluation of mechanical and alcohol-assisted epithelial separation. J Cataract Refract Surg. 2003; 29: 1496-1501.

21 Chen YT, Huang FC, Tseng SY et al. The cleavage plane of corneal epithelial adhesion complex in traumatic recurrent corneal erosion. Mol Vis.2006;12:196-204 
Legends for figures

Figure 1. Transmission electron microscopy of corneal epithelium upon mechanical debridement. A: Full thickness epithelium with electron dense, presumably proteinaceous material underneath (asterisk). Bar $=2.5 \mu \mathrm{m}$. B) Detail of well preserved lateral cell membranes with desmosomes. Bar $=0.25 \mu \mathrm{m} . \mathrm{C}$ ) Detail of basal cell layer, with hemidemosomes, proteinaceous debris (asterisk) and cell blebs (arrowhead) underneath. Bar $=0.5 \mu \mathrm{m}$.

Figure 2. Transmission electron microscopy of corneal epithelium upon ALD. A) Detail of well preserved lateral cell membranes with intact desmosomes. Bar $=0.25 \mu \mathrm{m}$. B) Area of basal cell layer with attached basal lamina down to the lamina reticularis with anchoring fibrils (arrows); the arrowhead points to a hemidesmosome. Bar $=0.25 \mu \mathrm{m} . \mathrm{C}$ ) Alcohol induced artefacts: detachment of chromatin from the nuclear membrane in a nucleus $(\mathrm{N})$, and dark cells (above) alternating with clear cells (below; diamond). Bar $=0.6 \mu \mathrm{m} . \mathrm{D}$ ) Corresponding stromal surface of a corneal button from which the epithelium was removed by ALD, showing the lamina densa (thin arrows). The star indicates the previous location of the epithelium. Bar $=0.6 \mu \mathrm{m}$

Figure 3. Transmission electron microscopy of corneal epithelium removed by ALD in cases of traumatic RCE. A) Full thickness epithelial sheet Bar $=6 \mu \mathrm{m}$. B) Detail of well preserved lateral cell membranes with desmosomes. Bar $=0.125 \mu \mathrm{m}$. C) Detail of basal cell layer, with hemidemosomes (arrowheads). Bar $=0.125 \mu \mathrm{m}$. D) Area of basal cell layer with a thin, attached basal lamina down to the lamina reticularis with anchoring fibrils (arrows). The arrowheads point to hemidesmosomes. Bar $=0.125 \mu \mathrm{m}$.

Figure 4. Transmission electron microscopy of corneal epithelium from cases of RCE. A) Traumatic RCE; area of epithelial atrophy and interruption (double arrowhead) with proteinaceous 
material (asterisk) and cell blebs underneath. Bar $=3 \mu \mathrm{m}$. B) Traumatic RCE: area of basal cell layer with intact membrane but lacking hemidesmosomes and expanding into thin cell projections with the aspect of filopodia or lamellipodia. $\operatorname{Bar}=0.3 \mu \mathrm{m}$. C) Case of MDFD: the basal epithelial layer shows oedema (diamonds) and single cell degeneration (star) and has attached a thick basement membrane with multiple layers of basal lamina (asterisk. Bar $=3 \mu \mathrm{m}$. D) Case of MDFD: detail of the multilayered basal lamina (asterisk) with many anchoring fibrils (arrows); some hemidesmosomes are not attached to the basal lamina (arrowheads). $\mathrm{Bar}=0.6 \mu \mathrm{m}$. 


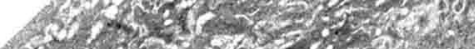

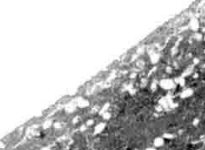

18. $3: 5$

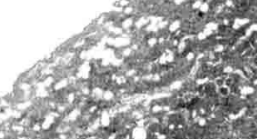
$0.03,5$ ?

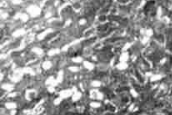

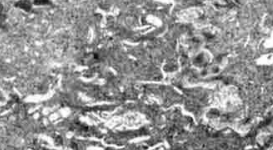

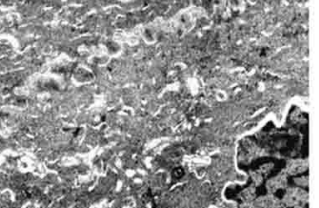

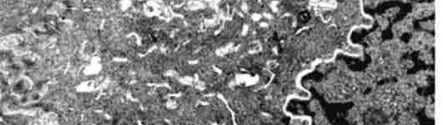
$92+\infty$

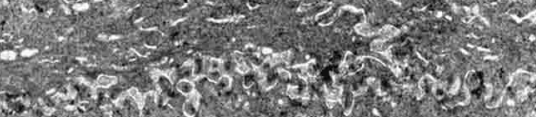
$20 \%$

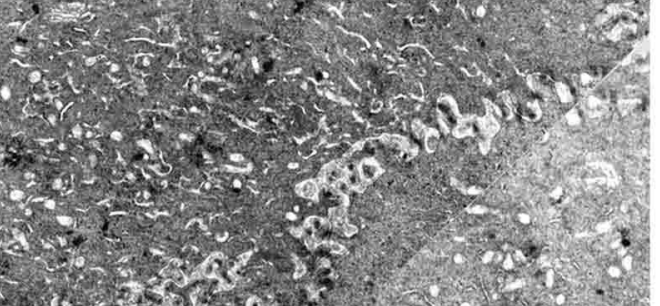

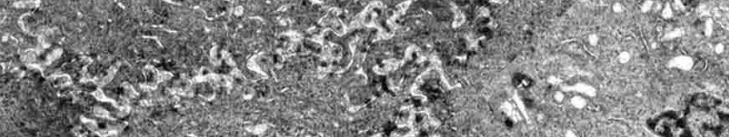

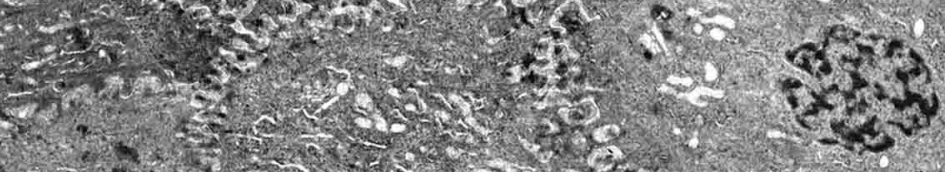

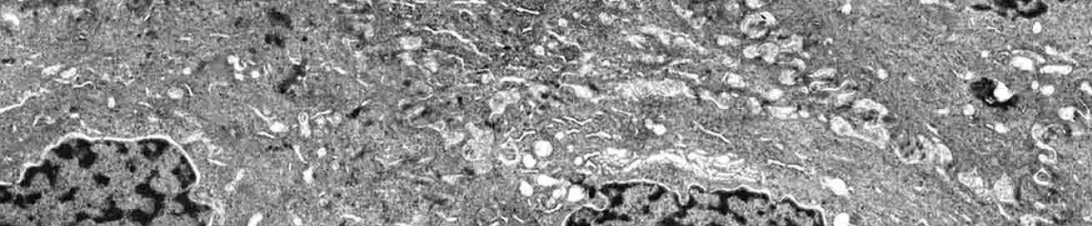
$-3$ $y=x$

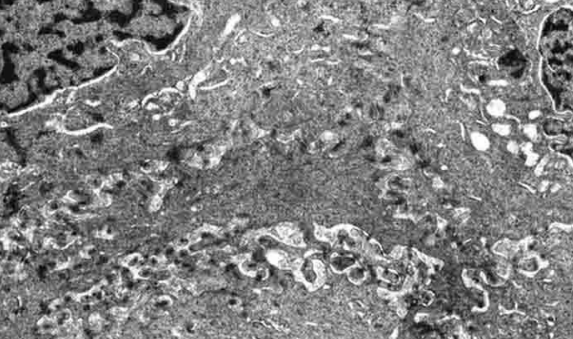

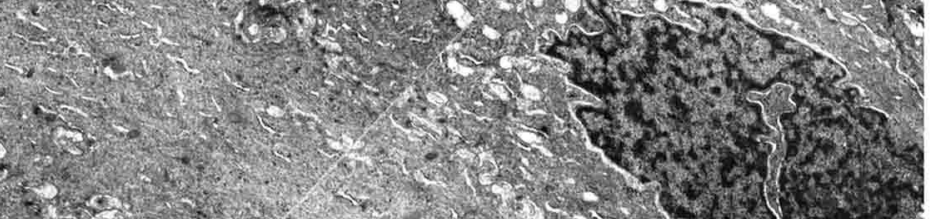
$x^{3}+\cos ^{2}$

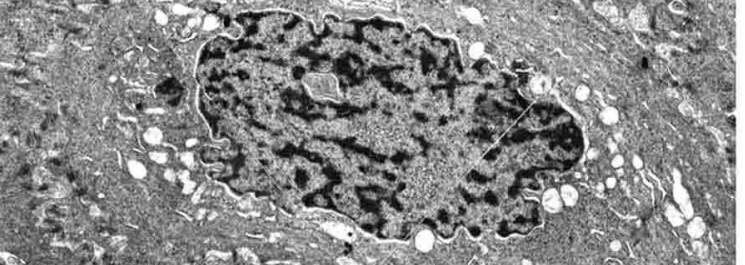
$1 \mathrm{~B}+2+2$

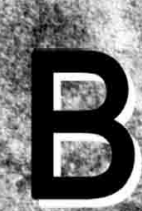

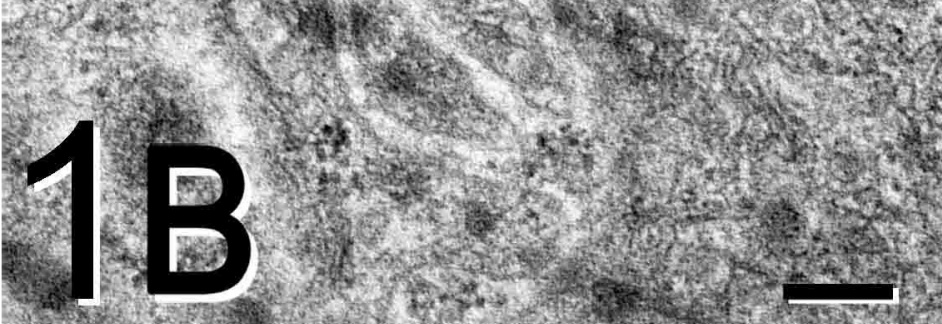

\section{3,1
3}

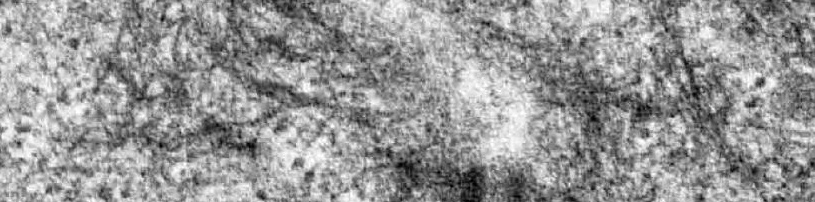

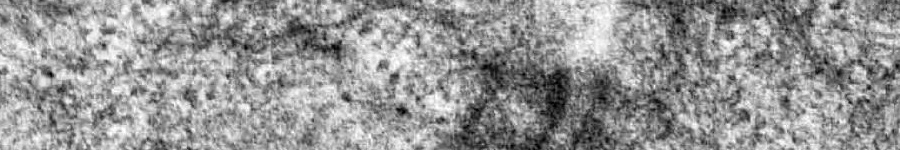

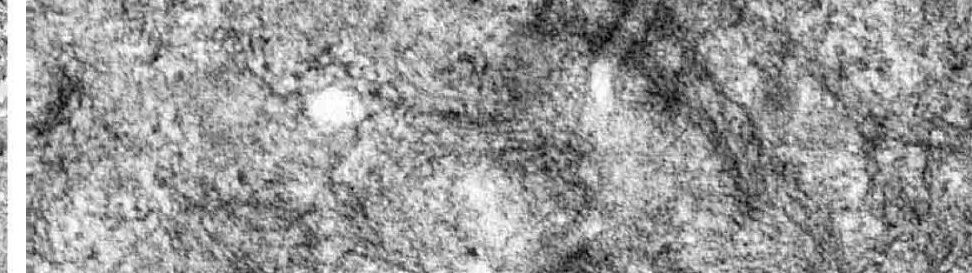

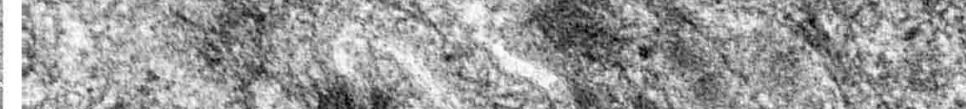

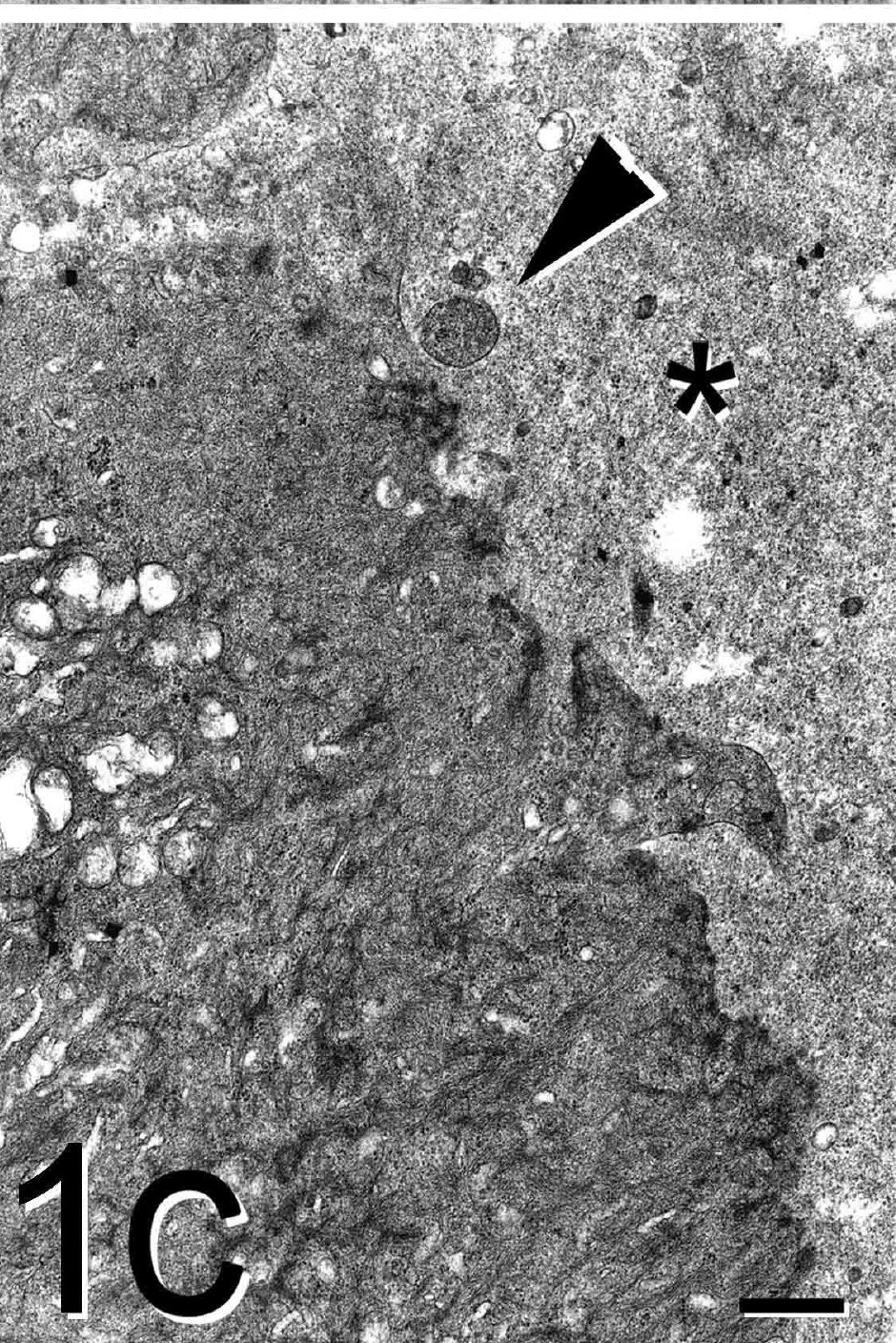

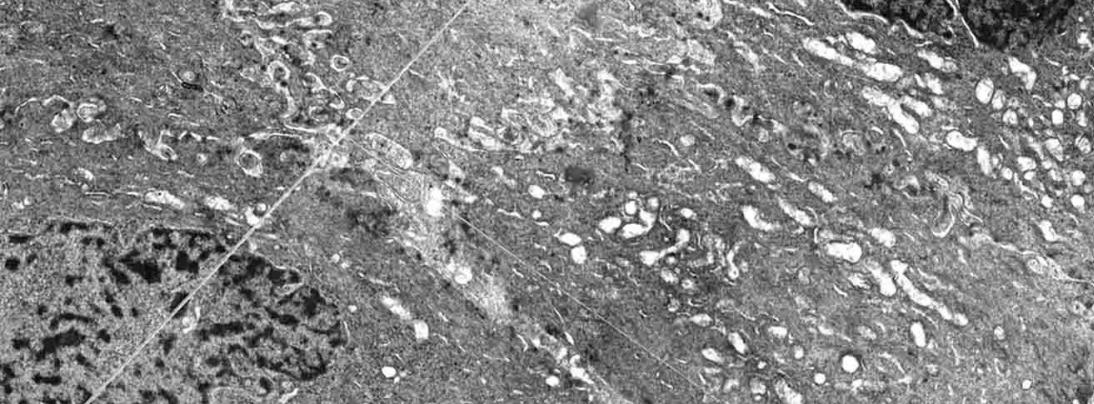

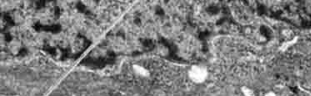

es

$08 \times-20$

1 


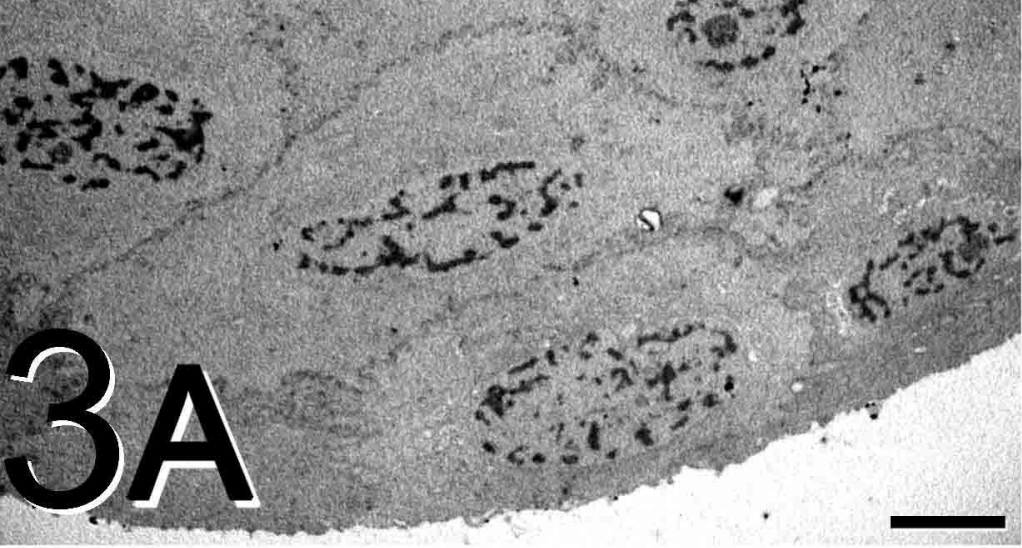

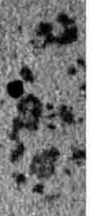

\section{0
$i=i^{2}$}

12139 W.

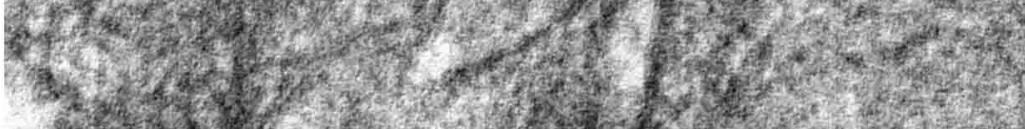
H.

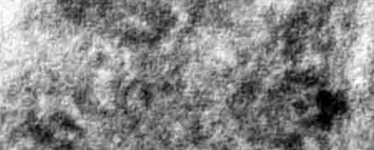

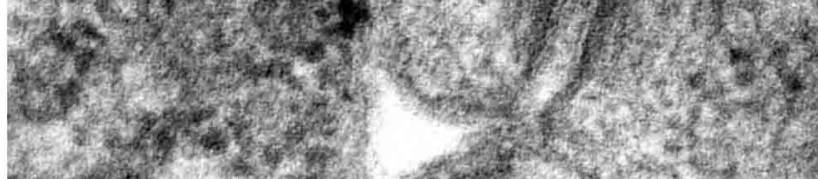

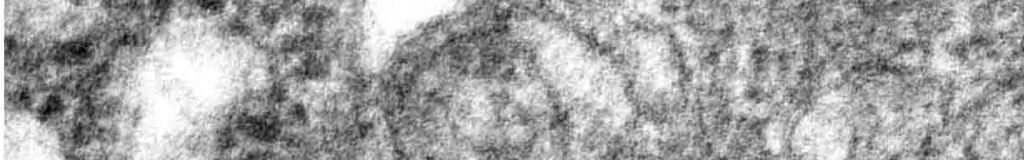

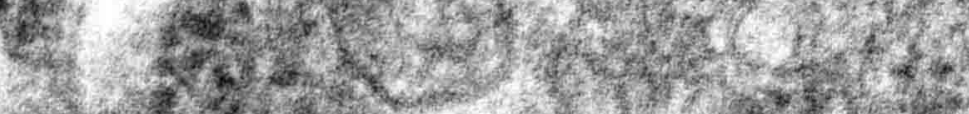

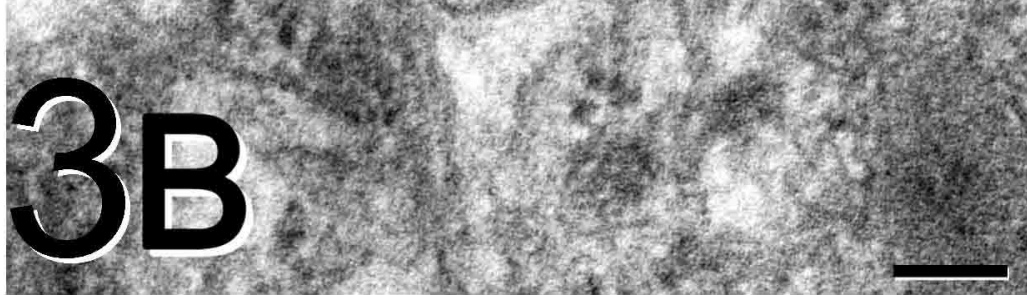
7. 4 yin

Q.

(4.7.

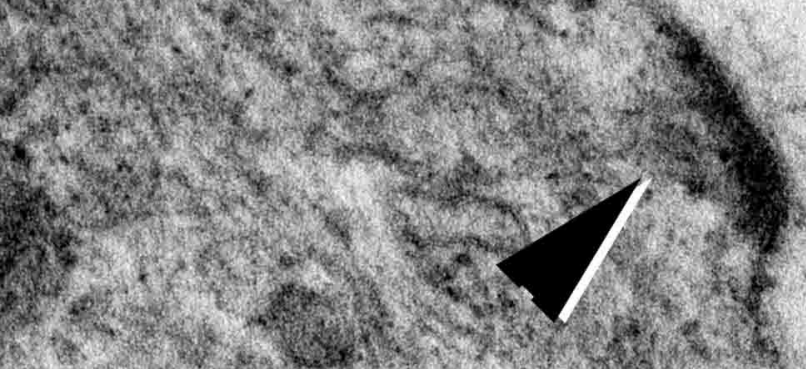

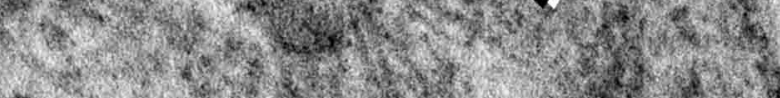

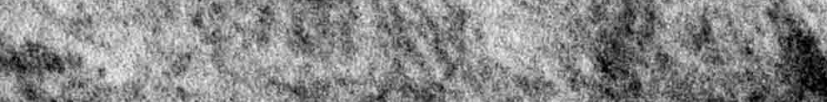

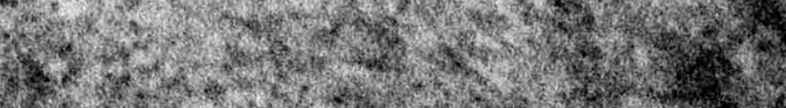

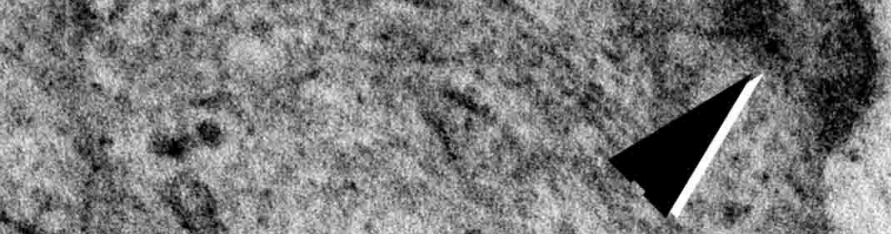

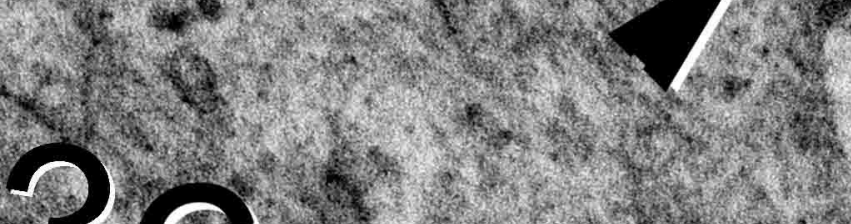

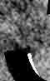

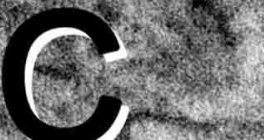

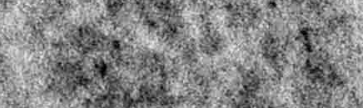

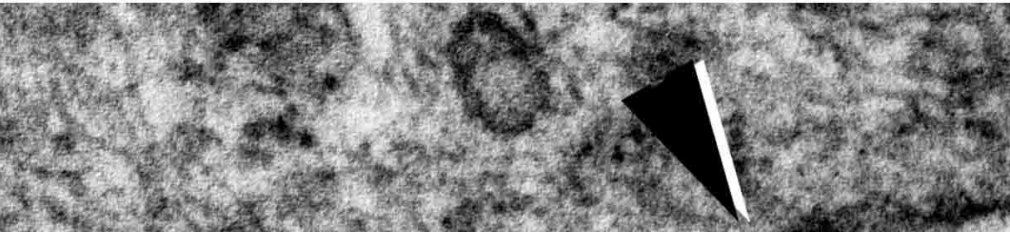
2. $5 x^{2} 3 y^{2}+1$
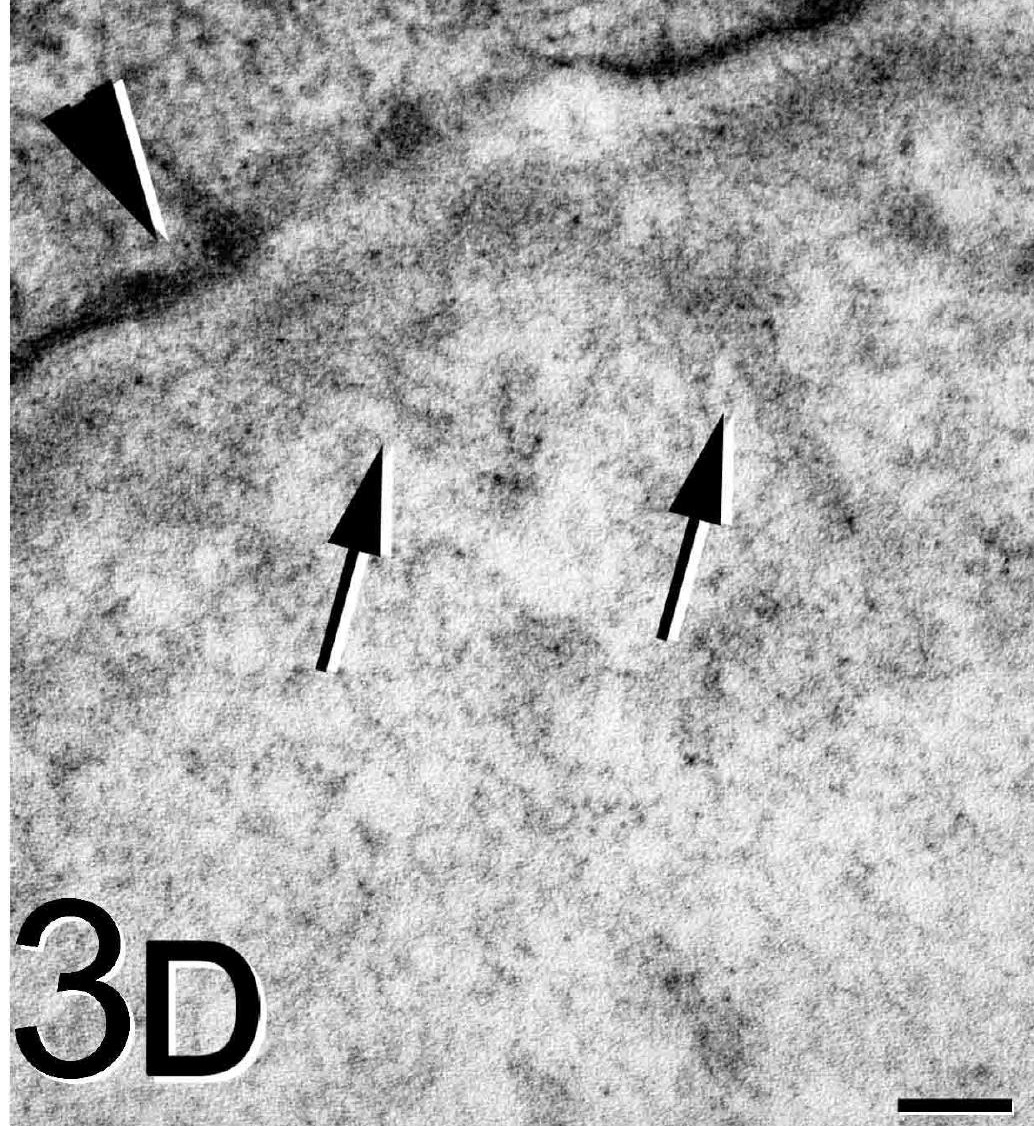


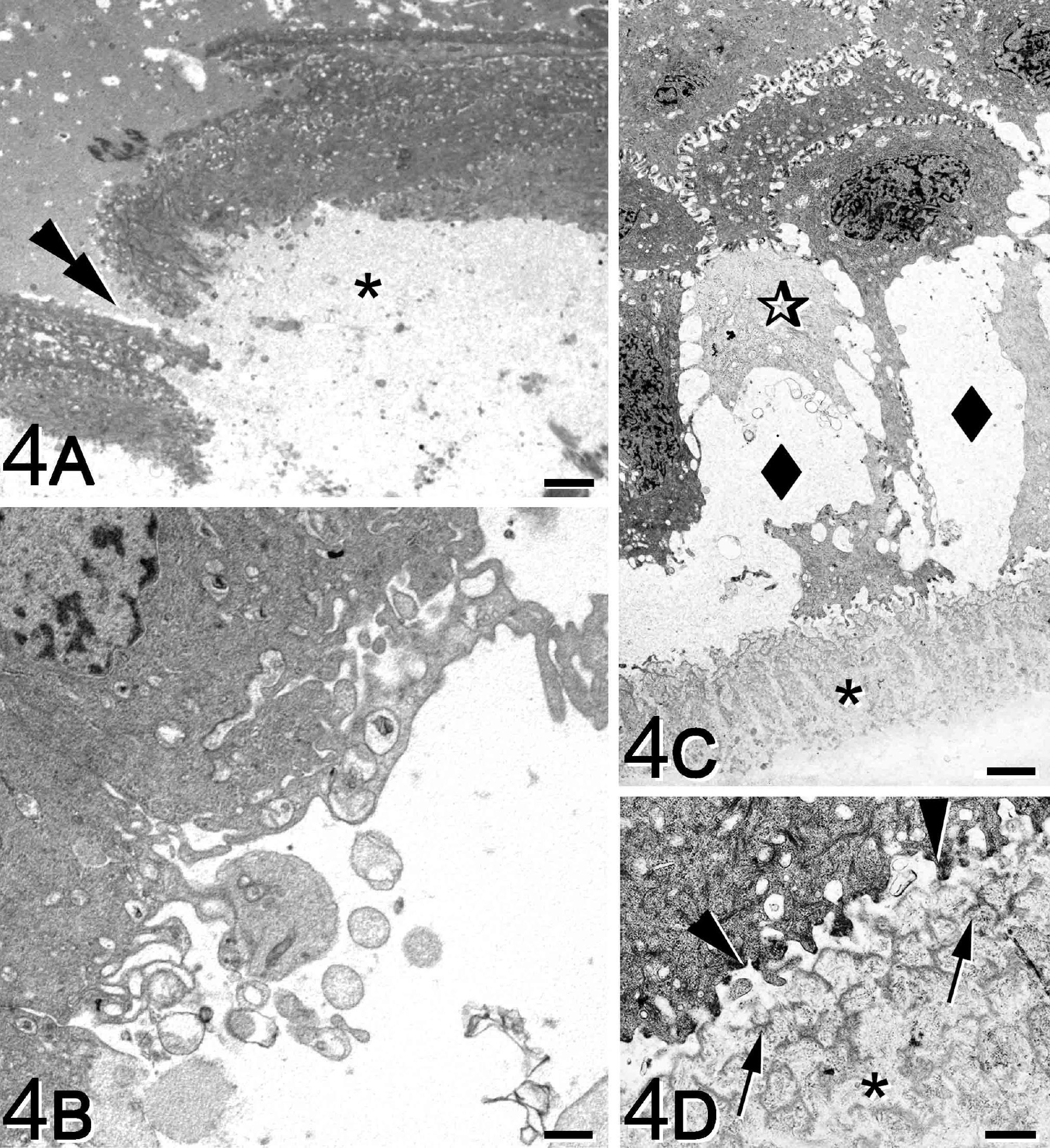

